\title{
Potential application of bacteriophage pVp-1: Agent combating Vibrio parahaemolyticus strains associated with acute hepatopancreatic necrosis disease (AHPND) in shrimp
}

\author{
Jin Woo Jun ${ }^{\mathrm{a}, 1}$, Jee Eun Han ${ }^{\text {b,1 }}$, Kathy F.J. Tang ${ }^{\mathrm{b}}$, Donald V. Lightner ${ }^{\mathrm{b}}$, Jaehoon Kim ${ }^{\mathrm{c}}$, \\ Sang Won Seo ${ }^{\mathrm{c}}$, Se Chang Park ${ }^{\mathrm{a}, *}$ \\ a Laboratory of Aquatic Biomedicine, College of Veterinary Medicine and Research Institute for Veterinary Science, Seoul National University, Seoul 151-742, Republic of Korea \\ b School of Animal and Comparative Biomedical Sciences, University of Arizona, Tucson, AZ, USA \\ c CTCBio Inc, 94 Saengmyeonggwahakgwan-gil Hongcheon-eup, Hongcheon-gun, Gangwon-do, Republic of Korea
}

\section{A R T I C L E I N F O}

\section{Article history:}

Received 4 January 2016

Received in revised form 11 February 2016

Accepted 12 February 2016

Available online 17 February 2016

\section{Keywords:}

Acute hepatopancreatic necrosis disease

(AHPND)

Early mortality syndrome (EMS)

Vibrio parahaemolyticus

Bacteriophage

Phage therapy

\begin{abstract}
A B S T R A C T
Acute hepatopancreatic necrosis disease (AHPND, also known as early mortality syndrome, EMS) caused by Vibrio parahaemolyticus has resulted in severe marine shrimp mortality and significant economic losses in related aquaculture throughout Southeast Asia and Central America. As no viable remedy has yet been reported, the main objective of this study was to develop an effective bacteriophage (phage)-based method of controlling AHPND/EMS. To determine the bacteriolytic activity of phage pVp-1 against $V$. parahaemolyticus strains causing AHPND/EMS, its infectivity was tested on 22 strains isolated from geographically diverse regions ( 5 of the Asian type and 17 of the Mexican type). This phage was able to infect $90.9 \%$ (20 strains among 22 strains) of the AHPND/EMS-related V. parahaemolyticus strains used in this study, and demonstrated substantial bacteriolytic activity against three strains known to be highly pathogenic. To the best of our knowledge, this is the first report of a virulent phage infecting $V$. parahaemolyticus strains responsible for AHPND/EMS, and indicates the potential utility of pVp-1 in phage therapy.
\end{abstract}

(c) 2016 Elsevier B.V. All rights reserved.

\section{Introduction}

Vibrio species are among the most abundant bacteria in marine environments (Thompson et al., 2004). Of these, V. anguillarum, V. harveyi, and $V$. parahaemolyticus are known to be pathogenic to shrimp (Lightner and Mc Vey, 1993). Certain strains of the latter cause acute hepatopancreatic necrosis disease (AHPND, also known as early mortality syndrome, EMS), which have resulted in severe mortality (up to $100 \%$ ) in aquacultures of the marine shrimp Penaeus vannamei and $P$. monodon (Flegel, 2012; Leaño and Mohan, 2012; Lightner et al., 2012). This disease has caused significant economic losses in China since 2009, Southeast Asia (including Thailand, Vietnam, and Malaysia) since 2011, and Central American countries such as Mexico (since 2013), Costa Rica (from 2015), and Honduras (also from 2015) (NACA, 2012; Soto-Rodriguez et al., 2015; Zhang et al., 2012). As antibiotics are considered the standard treatment for this disease, they have frequently been used as prophylaxis or therapy for AHPND/EMS (Han et al., 2015a; Neela et al., 2007). The most commonly used of these is tetracycline (Neela et al., 2007). However, the imprudent use of antibiotics

\footnotetext{
* Corresponding author.

E-mail address: parksec@snu.ac.kr (S.C. Park).

1 These authors contributed equally to this work.
}

has led to increasing numbers of antibiotic-resistant bacterial strains (Han et al., 2015a; Neela et al., 2007). For instance, according to a previous report (Han et al., 2015a), V. parahaemolyticus strains associated with AHPND/EMS in Mexico were found to be resistant to oxytetracycline and exhibited a high level of resistance to tetracycline.

Phages, viruses that infect bacteria, can be used to control infectious diseases in humans, animals, and plants (Biswas et al., 2002; Bruttin and Brűssow, 2005; Chhibber et al., 2008; Kumari et al., 2009; Nagy et al., 2012; Sulakvelidze and Kutter, 2005; Vinodkumar et al., 2005). Phages have been proposed as an alternative method since they show an effective bacteriolytic activity and possess advantages over conventional antibiotics: phages are natural and relatively inexpensive (Gutiérrez et al., 2010; Sulakvelidze and Kutter, 2005). More importantly, no serious side effects of phage therapy have been reported to date (Gutiérrez et al., 2010; Sulakvelidze and Kutter, 2005). Recently, an acceleration of phage therapy research has become desirable due to the increase of antibiotic-resistant bacteria, the limited choice of effective treatments, and a delay in the development of novel antibiotics (Hagens and Loessner, 2010). Considering the lack of feasible remedies reported for AHPND/EMS, the development of effective treatment methods is necessary.

In our previous study, we described a virulent Siphoviridae phage, pVp-1, capable of infecting V. parahaemolyticus (Jun et al., 2014b). 
pVp-1 showed effective bacteriolytic activity against 20 (74\%) of 27 multiple-antibiotic-resistant $V$. parahaemolyticus strains (Jun et al., $2014 \mathrm{~b})$. The aim of the present study was to determine whether phage pVp-1 induces effective bacteriolysis of AHPND/EMS-associated pathogenic strains isolated from geographically diverse regions.

\section{Materials and methods}

\subsection{AHPND/EMS-related bacterial isolates and DNA extraction}

The V. parahaemolyticus strains associated with AHPND/EMS analyzed in this study are shown in Table 1 . These bacterial isolates were obtained from pond water, sediment samples, and the stomachs of shrimp affected by AHPND/EMS in Southeast Asia and Central America. Pure cultures were obtained by streaking on $2 \% \mathrm{NaCl}$ tryptic soy agar (TSA) plates.

For DNA extraction from pure bacterial cultures, each isolate was grown in $2 \% \mathrm{NaCl}$ tryptic soy broth (TSB) at $28-29^{\circ} \mathrm{C}$ with gentle shaking $(100 \mathrm{rpm})$. The culture was then centrifuged at $5000 \times \mathrm{g}$ for $5 \mathrm{~min}$, and the resulting pellet was resuspended in $1 \mathrm{ml}$ water before being boiled for $10 \mathrm{~min}$

\subsection{AHPND/EMS identification and typing}

Conventional PCR assays were conducted to amplify pirA- and pirBlike genes for AHPND/EMS-associated $V$. parahaemolyticus identification, as previously described (Han et al., 2015c). PCR targeting a Tn3like transposon region was performed for plasmid typing (Han et al., 2015b).

\subsection{Phage host range and efficiency of plating (EOP) analysis}

The phage's host range was determined by spot test. Ten microliter of concentrated phage lysate $\left(>10^{9} \mathrm{PFU} / \mathrm{ml}\right)$ was added dropwise to a TSA plate overlaid with AHPND/EMS-associated $V$. parahaemolyticus cells $\left(10^{9} \mathrm{CFU} / \mathrm{ml}\right)$. The plate was allowed to dry and then incubated overnight. The spots were classified into three categories according to their clarity: clear, turbid, and no reaction. These phage activity tests were repeated three times to obtain reliable results. Plaque-forming units (PFU) assays were performed using a conventional double-layer agar method (Adams, 1959). EOP values were determined by calculating the ratio of the PFU value obtained with each phage- susceptible strain to that observed with the indicator strain ( $V$. parahaemolyticus 13-028/A3).

\section{Results and discussion}

\subsection{AHPND/EMS-associated V. parahaemolyticus identification and typing}

A total of $22 \mathrm{~V}$. parahaemolyticus strains responsible for AHPND/EMS were isolated from shrimp aquaculture environments and shrimp themselves in various geographical locations, and identified using PCR amplification with specific primers (Table 1 ). The typing method used revealed that five strains (isolated from Vietnam) belonged to the Asian type, while 17 strains (Mexico, three; Costa Rica, four; Honduras, two; Central American country 1, one; Central American country 2, six; Central American country 3, one) belonged to the Mexican type. In this study, the isolate typing results were consistent with the locations from which samples were sourced, as previously established using plasmid-based PCR (Han et al., 2015b).

\subsection{Bacteriolytic activity of phage $p V p-1$}

To evaluate the host range of pVp-1, its infectivity was tested on 22 strains of AHPND/EMS-associated $V$. parahaemolyticus. This phage infected 90.9\% (20 strains among 22 strains) of AHPND/EMS $V$. parahaemolyticus strains isolated from geographically diverse regions, demonstrating that $\mathrm{pVp}-1$ has a broad host range, as previously reported (Jun et al., 2014b). pVp-1 inhibited all (5/5) of the Asian type strains, and $88.23 \%$ (15/17) of the Mexican type strains, infecting all of those tested but for two strains isolated from Honduras. In our previous study, pVp-1 presented its broad host range toward multiple-antibioticresistant V. parahaemolyticus strains (Jun et al., 2014b). Considering that Siphoviridae phages are generally believed to have restricted host ranges (Wichels et al., 1998), these results highlight the unique characteristics of pVp-1. This phage formed clear plaques on plates of $15(75 \%)$ of the 20 strains infected by $p V p-1$, including those from Vietnam $(2 / 5)$, Mexico (3/3), Costa Rica (4/4), and Central America Countries $1(1 / 1)$ and $2(5 / 6)$

The EOP varied among strains, with three (14-188/1, 15-142-32, and 15-234-18) exhibiting higher values than the indicator host strain (Table 1). Furthermore, pVp-1 was able to infect three representative AHPND/EMS-associated $V$. parahaemolyticus strains, resulting in clear plaques (Fig. 1) and high EOPs ( $\geq 0.91)$. These strains: 13-028/A3

Table 1

Bacterial strains used in this study and infectivity of Vibrio phage pVp-1.

\begin{tabular}{|c|c|c|c|c|c|}
\hline Bacterial species & Strain & Source & Host range $^{\mathrm{a}}$ (EOPs) & EMS type & Reference \\
\hline V. parahaemolyticus & $\begin{array}{l}13-028 / \mathrm{A} 3 \\
14-188 / 1 \\
14-188 / 2 \\
\text { VpK } \\
12-194 / \mathrm{g} \\
13-511 / \mathrm{A} 1 \\
13-306 \mathrm{D} / 4 \\
14-231 / \mathrm{D} 74 \\
15-341-3 \\
15-341-7 \\
15-341-12 \\
15-342-3 \\
15-289-2 \\
15-289-20 \\
15-118-30 \\
15-142-32 \\
15-142-33 \\
15-234-17 \\
15-234-18 \\
15-234-22 \\
15-234-27 \\
15-268 / \mathrm{A} 3\end{array}$ & $\begin{array}{l}\text { Vietnam } \\
\text { Vietnam } \\
\text { Vietnam } \\
\text { Vietnam } \\
\text { Vietnam } \\
\text { Mexico } \\
\text { Mexico } \\
\text { Mexico } \\
\text { Costa Rica } \\
\text { Costa Rica } \\
\text { Costa Rica } \\
\text { Costa Rica } \\
\text { Honduras } \\
\text { Honduras } \\
\text { Central America } 1 \\
\text { Central America } 2 \\
\text { Central America } 2 \\
\text { Central America } 2 \\
\text { Central America } 2 \\
\text { Central America } 2 \\
\text { Central America } 2 \\
\text { Central America } 3\end{array}$ & $\begin{array}{l}++(1.00) \\
+(3.80) \\
++(0.76) \\
+(0.35) \\
+(0.15) \\
++(0.95) \\
++(0.91) \\
++(0.21) \\
++(0.35) \\
++(0.86) \\
++(0.65) \\
++(0.38) \\
- \\
- \\
++(0.45) \\
+(3.55) \\
++(0.93) \\
++(0.17) \\
++(6.20) \\
++(0.64) \\
++(0.21) \\
+(0.12)\end{array}$ & $\begin{array}{l}\text { Asia } \\
\text { Asia } \\
\text { Asia } \\
\text { Asia } \\
\text { Asia } \\
\text { Mexico } \\
\text { Mexico } \\
\text { Mexico } \\
\text { Mexico } \\
\text { Mexico } \\
\text { Mexico } \\
\text { Mexico } \\
\text { Mexico } \\
\text { Mexico } \\
\text { Mexico } \\
\text { Mexico } \\
\text { Mexico } \\
\text { Mexico } \\
\text { Mexico } \\
\text { Mexico } \\
\text { Mexico } \\
\text { Mexico }\end{array}$ & $\begin{array}{l}\text { Tran et al. (2013) } \\
\text { Han et al. (2015b) } \\
\text { Han et al. (2015b) } \\
\text { Han et al. (2015b) } \\
\text { Nunan et al. (2014) } \\
\text { Nunan et al. (2014) } \\
\text { Han et al. (2015c) }\end{array}$ \\
\hline
\end{tabular}

a ++ , clear plaque; + , turbid plaque; - , no plaque. 


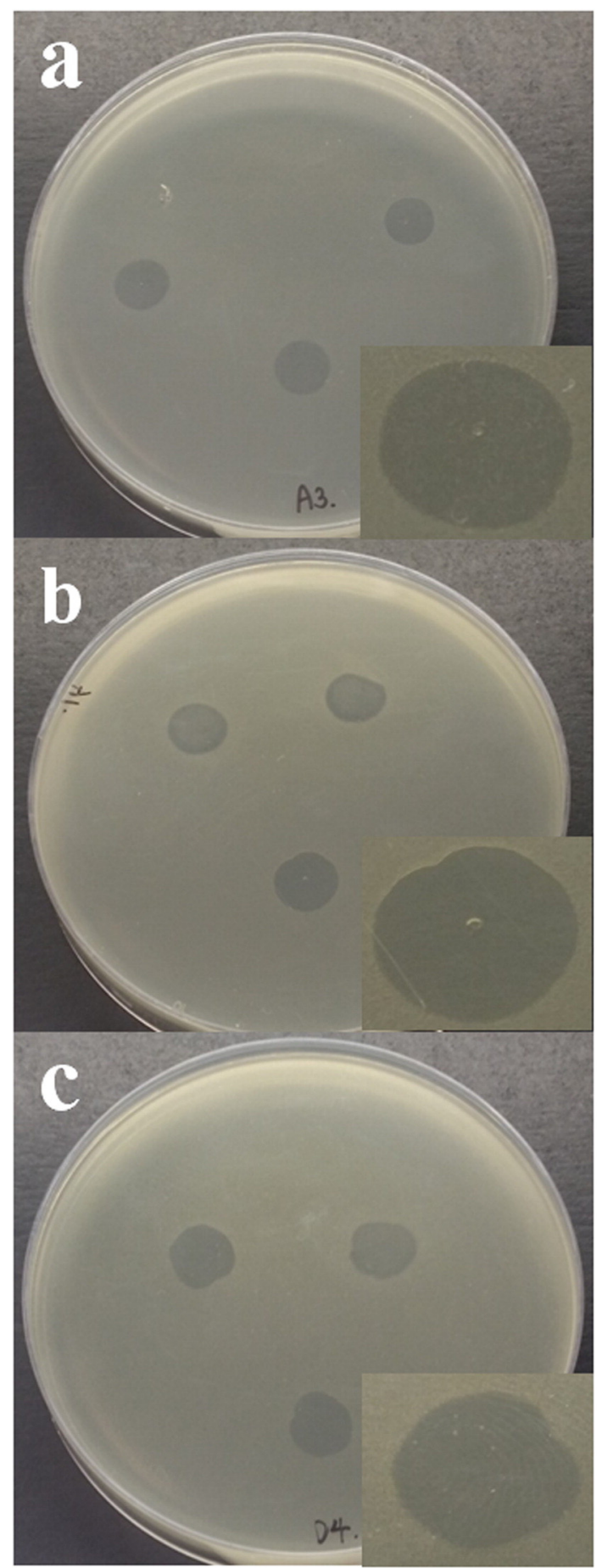

Fig. 1. Bacteriolytic activity of pVp-1 and its enlarged morphology against three representative AHPND/EMS V. parahaemolyticus strains: 13-028/A3 (a), Vietnam isolate; 13-511/A1 (b) and 13-306D/4 (c), Mexico isolates.

(from Vietnam), 13-511/A1, and 13-306D/4 (both from Mexico) were defined as representative isolates as they are known to be highly pathogenic to shrimp, causing $100 \%$ mortality within 24 hours postinfection (data not shown).

In our previous study, the therapeutic efficacy of $\mathrm{pVp}-1$ was emphasized via a series of phage treatment trials in a mouse model of infection with a multiple-antibiotic-resistant $V$. parahaemolyticus pandemic strain (Jun et al., 2014b). In that investigation, the administration of pVp-1 at high doses did not negatively affect the physical condition or survival of the mice during the whole observation period (Jun et al., 2014b). In a separate study conducted using two models of oyster infection, we demonstrated that $\mathrm{pVp}-1$ is effective in controlling $V$. parahaemolyticus infection by bath immersion, and inhibits bacterial growth when applied to the oyster-surface (Jun et al., 2014a). As this phage did not cause any harm to oysters (Jun et al., 2014a), we expect no serious side effects to result from its use on shrimp.

The results of the current study imply that further research regarding the application of pVp-1 in shrimp aquaculture is justified. Despite the potential utility of $\mathrm{pVp}-1$ in treating AHPND/EMS-related $V$. parahaemolyticus infection, further studies involving its use in a bona fide shrimp aquaculture environment are required. Moreover, in vivo experiments are now in progress to evaluate the protective effects conferred on shrimp by this phage.

\section{Acknowledgments}

We would like to thank all the staff at the School of Animal and Comparative Biomedical Sciences, University of Arizona, Tucson, AZ, USA for their assistance during the current study. This research was supported by the Basic Science Research Program through the National Research Foundation of Korea (NRF) funded by the Ministry of Education, Republic of Korea (2014R1A2A1A11050093).

\section{References}

Adams, M., 1959. Bacteriophages. Interscience Publishers, New York.

Biswas, B., Adhya, S., Washart, P., Paul, B., Trostel, A.N., Powell, B., Carlton, R., Merril, C.R. 2002. Bacteriophage therapy rescues mice bacteremic from a clinical isolate of vancomycin-resistant Enterococcus faecium. Infect. Immun. 70, 204-210.

Bruttin, A., Brűssow, H., 2005. Human volunteers receiving Escherichia coli phage T4 orally: a safety test of phage therapy. Antimicrob. Agents Chemother. 49, 2874-2878.

Chhibber, S., Kaur, S., Kumari, S., 2008. Therapeutic potential of bacteriophage in treating Klebsiella pneumoniae B5055-mediated lobar pneumonia in mice. J. Med. Microbiol. 57, 1508-1513.

Flegel, T.W., 2012. Historic emergence, impact and current status of shrimp pathogens in Asia. J. Invertebr. Pathol. 110, 166-173.

Gutiérrez, D., Martinez, B., Rodriguez, A., Garcia, P., 2010. Isolation and characterization of bacteriophages infecting Staphylococcus epidermidis. Curr. Microbiol. 61, 601-608.

Hagens, S., Loessner, M.J., 2010. Bacteriophage for biocontrol of foodborne pathogens: calculations and considerations. Curr. Pharm. Biotechnol. 11, 58-68.

Han, J.E., Mohney, L.L., Tang, K.F.J., Pantoja, C.R., Lightner, D.V., 2015a. Plasmid mediated tetracycline resistance of Vibrio parahaemolyticus associated with acute hepatopancreatic necrosis disease (AHPND) in shrimps. Aquacult. Rep. 2, 17-21.

Han, J.E., Tang, K.F.Y., Lightner, D.V., 2015b. Genotyping of virulence plasmid from Vibrio parahaemolyticus isolates causing acute hepatopancreatic necrosis disease in shrimp. Dis. Aquat. Org. 115, 245-251.

Han, J.E., Tang, K.F.J., Tran, L.H., Lightner, D.V., 2015c. Photorhabdus insect-related (Pir) toxin-like genes in a plasmid of Vibrio parahaemolyticus, the causative agent of acute hepatopancreatic necrosis disease (AHPND) of shrimp. Dis. Aquat. Org. 113, 33-40.

Jun, J.W., Kim, H.J., Yun, S.K., Chai, J.Y., Park, S.C., 2014a. Eating oysters without risk of vibriosis: application of a bacteriophage against Vibrio parahaemolyticus in oysters. Int. J. Food Microbiol. 188, 31-35.

Jun, J.W., Shin, T.H., Kim, J.H., Shin, S.P., Han, J.E., Heo, G.J., De Zoysa, M., Shin, G.W., Chai, J.Y., Park, S.C., 2014b. Bacteriophage therapy of a Vibrio parahaemolyticus infection caused by a multiple antibiotic resistant 03:K6 pandemic clinical strain. J. Infect. Dis. $210,72-78$.

Kumari, S., Harjai, K., Chhibber, S., 2009. Efficacy of bacteriophage treatment in murine burn wound infection induced by Klebsiella pneumoniae. J. Microbiol. Biotechnol. 19, 622-628.

Leaño, E.M., Mohan, C.V., 2012. Early mortality syndrome threatens Asia's shrimp farms. Glob. Aquacult. Advocate, pp. 38-39 (July/Aug).

Lightner, D.V., Mc Vey, J.P., 1993. Diseases of Cultured Penaeid Shrimp. CRC Press, Boca Raton, USA, pp. 393-486.

Lightner, D.V., Redman, R.M., Pantoja, C.R., Noble, B.L., Tran, L.H., 2012. Early mortality syndrome affects shrimp in Asia. Glob. Aquacult. Advocate, p. 40 (Jan/Feb).

NACA, 2012. Asia Pacific Emergency Regional Consultation on the Emerging Shrimp Disease: Early Mortality Syndrome (EMS)/Acute Hepatopancreatic Necrosis Syndrome (AHPNS). Network of Aquaculture Centres in Asia-Pacific Bangkok, Thailand (August 9-10).

Nagy, J.K., Király, L., Schwarczinger, I., 2012. Phage therapy for plant disease control with a focus on fire blight. Cent. Eur. J. Biol. 7, 1-12.

Neela, F.A., Nonaka, L., Suzuki, S., 2007. The diversity of multi-drug resistance profiles in tetracycline-resistant Vibrio species isolated from coastal sediments and seawater. J. Microbiol. 45, 64-68.

Nunan, L., Lightner, D., Pantoja, C., Gomez-Jimenez, S., 2014. Detection of acute hepatopancreatic necrosis disease (AHPND) in Mexico. Dis. Aquat. Org. 111, 81-86.

Soto-Rodriguez, S.A., Gomez-Gill, B., Lozano-Olvera, R., Betancourt-Lozano, M., MoralesCovarrubias, M.S., 2015. Field and experimental evidence of Vibrio parahaemolyticus as the causative agent of acute hepatopancreatic necrosis disease of cultured shrimp 
(Litopenaeus vannamei) in Northwestern Mexico. Appl. Environ. Microbiol. 81, 1689-1699.

Sulakvelidze, A., Kutter, E., 2005. Bacteriophage therapy in humans. In: Kutter, E., Sulakvelidze, A. (Eds.), Bacteriophages: Biology and Application. CRC Press, Boca Raton, pp. 381-436.

Thompson, F.L., Iida, T., Swings, J., 2004. Biodiversity of Vibrios. Microbiol. Mol. Biol. Rev. 68, 403-431.

Tran, L., Nunan, L., Redman, R.M., Mohney, LL, Pantoja, C.R., Fitzsimmons, K., Lightner, D.V., 2013. Determination of the infectious nature of the agent of acute hepatopancreatic necrosis syndrome affecting penaeid shrimp. Dis. Aquat. Org. 105, $45-55$
Vinodkumar, C.S., Neelagund, Y.F., Kalsurmath, S., 2005. Bacteriophage in the treatment of experimental septicaemia mice from a clinical isolate of multidrug resistant Klebsiella pneumoniae. J. Commun. Dis. 37, 18-29.

Wichels, A., Biel, S.S., Gelderblom, H.R., Brinkhoff, T., Muyzer, G., Schütt, C., 1998. Bacteriophage diversity in the North Sea. Appl. Environ. Microbiol. 64, 4128-4133.

Zhang, B.C., Liu, F., Bian, H.H., Liu, J., Pan, L.Q., Huang, J., 2012. Isolation, identification, and pathogenicity analysis of a Vibrio parahaemolyticus strain from Litopenaeus vannamei. Prog. Fish. Sci. 33, 56-62. 